\title{
Functioning gonadotropic adenoma
}

INSERM

\section{Source}

INSERM. (1999). Orphanet: an online rare disease and orphan drug data base.

Functioning gonadotropic adenoma. ORPHA:91348

Functioning gonadotropic adenoma is a very rare pituitary tumor, macroscopically

characterized by a soft, well vascularized, variable sized adenoma, with occasional areas

of hemorrage or necrosis, that secretes biologically active gonadotropins. In addition to common neurological signs due to mass effect (headache and/or visual field deterioration), additional clinical manifestations include menstrual irregularities (secondary amenorrhea, oligomenorhea or severe menorrhagia), galactorrhea, infertility or ovarian hyperstimulation syndrome (in premenopausal women), testicular enlargement and, occasionally, hypogonadism (in men) and isosexual precocious puberty (in children). 